\title{
Growth factors and gut function
}

\author{
N. J. Seare ${ }^{1}$ and R. J. Playford ${ }^{2 *}$ \\ ${ }^{1}$ Research Office and ${ }^{2}$ University Division of Gastroenterology, Leicester General Hospital, \\ Gwendolen Road, Leicester LE5 4PW, UK
}

\section{Functions of the gastrointestinal tract}

The gastrointestinal tract is a complex system with several diverse functions related to the interactions between food and the body. In addition to the functions of digestion and absorption, the gastrointestinal epithelium plays a vital role as a barrier against lumen acid, proteolytic enzymes, and ingested noxious agents. It should also be noted that the gastrointestinal tract is a major endocrine organ, producing many 'gut' hormones and acts as a focus for humoral and cellular immunity. The barrier function of the gut is dependent on the constant renewal of the epithelium and, in the stomach and the colon, on the presence of an overlying adherent mucus gel. The epithelial layer is one of the most rapidly proliferating tissues in the body, with a dynamic equilibrium existing in the rates of cell production, migration, and cell loss (which includes apoptosis and surface shedding).

When a mucosal injury occurs, it is generally rapidly repaired by a combination of increased cell migration, 'restitution', which begins within the first hour following injury (Svanes et al. 1982), and proliferation and remodelling, which only begins 1-2 d after the injury has occurred.

The current published literature on the gastrointestinal tract and its function shows that at least twenty different peptides, mainly with growth factor activity, play key roles in the maintenance and restoration of gastrointestinal mucosal integrity, with the list continuing to grow. The present paper looks at the role of these factors in the gastrointestinal tract in health and disease. Because of the broad nature of this topic, the reader is referred to appropriate reviews of specialist areas throughout the text.

\section{Cytokines and growth factors}

Cytokines and growth factors are extracellular signalling proteins or peptides. The cytokines are generally considered as local mediators involved in cell-to-cell communication, whilst the original definition of growth factors was on the basis of their stimulation of growth or cell division. There is overlap between the two terms and differences in sites of action range from factors having diverse actions acting on multiple organs, such as epidermal growth factor (EGF) as shown in Table 1 , to relatively site-specific factors.

\section{Cytokines}

The protein molecules known as the cytokines have a broad range of cellular functions and are active in the picomolar to nanomolar concentration range. In general, cytokines do not regulate normal cellular homeostasis, but act to alter cellular metabolism during times of perturbation, for example in response to inflammation (Dinarello, 1994).

Cytokines trigger acute cellular responses, such as chemotaxis, protein synthesis and cellular differentiation. Cytokines can be broadly categorized according to the types

Table 1. Actions of epidermal growth factor on the gut (Adapted from Uribe \& Barret, 1997)

\begin{tabular}{lcl}
\hline Action & Effect & Possible secondary message \\
\hline Proliferation & $\uparrow$ & \\
Gastric acid secretion & $\downarrow$ & Protein kinase C cAMP \\
Bicarbonate secretion & $\uparrow$ & Prostaglandins \\
NaCl and glucose uptake & $\uparrow$ & Brush-border area, Na+-glucose cotransporter, lipids \\
Chloride secretion & $\uparrow$ and $\downarrow$ & Phosphatidylinositol 3-kinase \\
Pancreatic amylase (EC 3.2.1.1) secretion & $\uparrow$ and $\downarrow$ & cAMP phospholipase C (EC 3.1.4.3) \\
Mucus secretion & $\uparrow$ & Prostaglandins \\
Gl blood flow & $\uparrow$ & $\beta$-Adrenergic NO prostaglandins \\
Longitudinal smooth muscle contraction & $\uparrow$ & Prostaglandins \\
Circular smooth muscle contraction & $\uparrow$ & (desensitizes) not prostaglandins \\
Gastric emptying & $\downarrow$ & Cell-migration prostaglandins \\
Restitution & $\uparrow$ & Proliferation, polyamines, mucus, trefoil peptides \\
Permeability & $\uparrow$ & \\
Muscosal protection & &
\end{tabular}

GI, gastrointestinal; $\uparrow$, increased; $\downarrow$, decreased.

Abbreviations: EGF, epidermal growth factor; TGF, transforming growth factor.

*Corresponding author: Professor R. J. Playford, fax +44(0)116 258 8183, email rjp13@le.ac.uk 
Table 2. A selection of cytokines and their functions (Adapted from Sartor, 1994)

\begin{tabular}{|c|c|}
\hline Cytokine & Role \\
\hline IL-1 & Activation of macrophages, $\mathrm{T}$ lymphocytes \\
\hline IL-2 & $\begin{array}{l}\text { Proliferation and activation of } \mathrm{TH}_{1} \text { and cytotoxic } \\
\text { lymphocytes }\end{array}$ \\
\hline IL-6 & Stimulation of acute-phase response \\
\hline IL-8 & PMN chemotaxis \\
\hline IL-10 & Down-regulation of $\mathrm{TH}_{1}$ lymphocytes \\
\hline TNF- $\alpha$ & $\begin{array}{l}\text { Activation of macrophages, PMN, and mesenchymal } \\
\text { and endothelial cells }\end{array}$ \\
\hline
\end{tabular}

IL, interleukin; TNF, tumour necrosis factor; PMN, polymorphonuclear; $\mathrm{TH}_{1}$, T-helper subset 1.

of responses that they induce and/or the systems within which they act. A summary of selected cytokines important in the gastrointestinal tract is given in Table 2.

\section{Growth factors}

The list of peptides influencing growth of the gastrointestinal tract continues to grow. It has been difficult to understand how they can act in an integrated fashion, since their sites of production, mechanisms of action and changes in concentration at sites of injury appear to vary between one peptide and another. In an attempt to put these factors into a physiological context, we have suggested that they may be usefully considered as belonging to one of three main groups, based on their role in vivo (Playford, 1995).

Mucosal-integrity peptides. These peptides are expressed in the normal mucosa and are involved in maintaining normal mucosal integrity, including the control of proliferation and other functions of the non-damaged bowel. Examples of peptides which belong to this group include transforming growth factor $\alpha$ (TGF $\alpha$ ), which acts directly on the enterocytes to stimulate proliferation and migration (Barnard et al. 1995) and pancreatic secretory trypsin inhibitor which protects the overlying mucus protective layer from excessive digestion by lumen proteases (Playford et al. 1991).

Luminal-surveillance peptides. These peptides are continuously secreted into the lumen, but because their receptors are not present on the apical (luminal) aspects of the enterocytes, they can only stimulate growth and repair at sites of injury, where they can gain access to their receptor. Their predominant function is, therefore, to be readily available to stimulate repair at sites of gastrointestinal damage. The prime example of this is EGF (see below; Playford \& Wright, 1996).

Rapid-response peptides. These peptides are present in relatively low concentration under normal circumstances, but their production is rapidly up-regulated at sites of injury. A prime example of this is a member of the trefoil peptide family, spasmolytic polypeptide (also termed TFF2), which is up-regulated within $1 \mathrm{~h}$ of injury and contributes to the early phase of the repair process, particularly restitution (Playford et al. 1995b).

Some examples from each of these three groups will be discussed in further detail.

The transforming growth factor family. TGF $\alpha$ is produced in the mucosa throughout the gastrointestinal tract and binds to the same receptor as EGF. It is synthesized as a 160 amino acid precursor molecule that spans the cell membrane; subsequent exposure of the external domains to specific proteases releases a soluble fifty amino acid form. The biological function of the membrane-bound form is unclear, but may be associated with stimulation of 'EGF' receptors on the lateral membranes of adjacent cells via a paracrine mechanism. TGF $\alpha$ is trophic to a variety of cell lines and stimulates gut growth when infused systemically (Barnard et al. 1995). Most studies suggest that its role in the mucosa is to maintain normal epithelial integrity. In support of this idea, mice which have had the TGF $\alpha$ gene 'knocked out' have an increased sensitivity to colonic injury (Egger et al. 1997).

TGF $\beta$ represents a ubiquitous group of cytokines, structurally distinct from TGF $\alpha$, that exert a multiplicity of influences in a wide array of tissue and cell types. In the gastrointestinal tract, TGF $\beta$ inhibit proliferation in normal epithelial cell populations, but promote it in many mesenchymal tissues (Lamprecht et al. 1989; Baldwin \& Whitehead, 1994). Because of its distribution in the non-proliferative zones of the intestinal villi, it has been suggested that it may function as a 'mitotic brake' to prevent continued proliferation of the enterocytes as they leave the crypt zone. TGF $\beta$ is also thought to play a key role as an intermediate signal peptide in the pro-migratory effects of several other peptides involved in healing, such as EGF (Dignass \& Podolsky, 1993).

Epidermal growth factor. EGF is a fifty-three amino acid peptide (molecular weight 6400) which is continuously secreted into the gut lumen by the salivary glands and Brunner's glands of the duodenum. The concentration of EGF in human gastric juice is about $500 \mathrm{ng} / \mathrm{l}$. EGF is a potent stimulant of proliferation for a variety of gastrointestinal cell lines in vitro and is trophic to the bowel when infused intravenously (Goodlad et al. 1987). It is also a potent cytoprotective agent, able to stabilize cells against noxious agents such as ethanol or non-steroidal antiinflammatory drugs, via acid-independent means (Playford et al. 1995a).

The mechanisms underlying cytoprotection are poorly understood, but probably include stimulation of goblet cells to release mucus (Ishikawa et al. 1994) and increasing gastric blood flow (Hui et al. 1993). The fact that EGF is present in the gut lumen whereas its receptor is only present on the basolateral membranes of the bowel epithelium (Playford et al. 1996), strongly supports the idea that it functions as a luminal-surveillance peptide. Further details of the actions of EGF can be found in Table 1 .

Trefoil peptides. The trefoil peptide family in mammals consists of a group of small proteins, each containing one or two copies of the trefoil motif. This motif comprises a three-loop (trefoil) configuration with six highly-conserved cysteine residues allowing three interchain disulphide bridges (Fig. 1). In human subjects, the trefoil peptides are found in the mucus-producing epithelium in the stomach and small and large intestines. The trefoil peptides are thought to have two distinct functions in the gastrointestinal tract: under basal circumstances, they play a role in mucus stabilization; whilst when an acute injury occurs, their rapid up-regulation is important in stimulating the repair process, particularly that of restitution (Playford, 1997a). 
It is beyond the scope of the present review to discuss current research associated with the cytokines and growth factors in more detail. A table of reviews relating to this area is given in Table 3 .

\section{Breakdown in mucosal integrity}

The maintenance of mucosal homeostasis is thus dependent on multiple interrelated factors which form part of a highlyintegrated system. Mucosal integrity is maintained when the damaging effect of aggressive factors such as acid and digestive enzymes are counterbalanced by correct amounts of mucosal defence mechanisms such as proliferation, mucus layer and the presence of regulatory peptides (Fig. 2). This

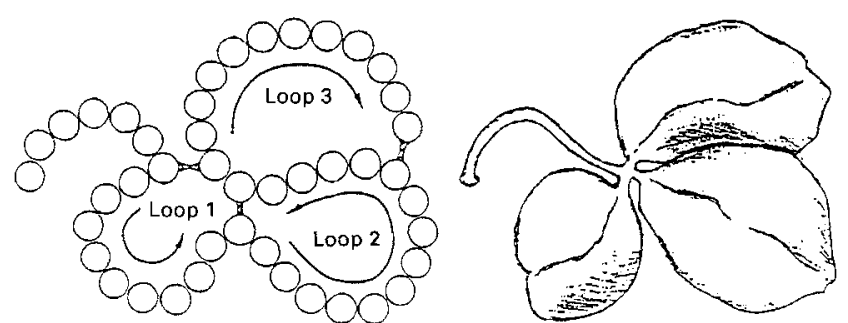

Fig. 1. Trefoil peptides derived their name from the suggestion that their structure resembled a three-leaf (trefoil) pattern.

Normal Gl tract

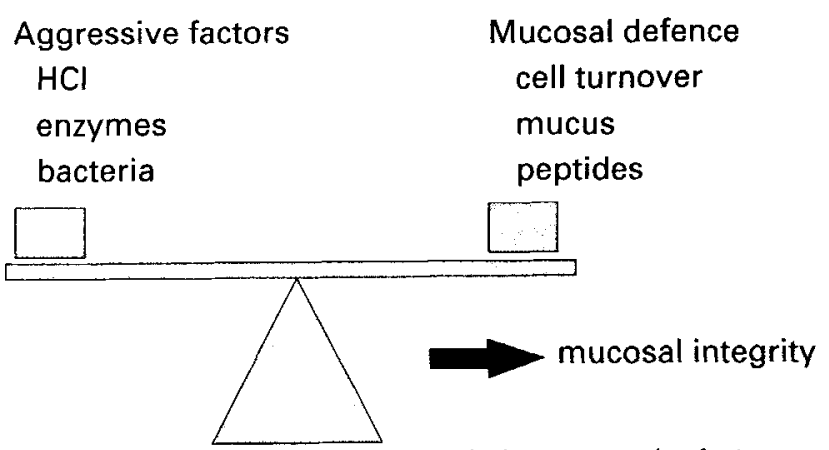

Fig. 2. Mucosal integrity is maintained when aggressive factors are balanced by mucosal defence. Gl, gastrointestinal. balance is lost, resulting in ulceration or injury, if there are excessive aggressive factors, e.g. colonization with toxic bacteria such as Helicobacter pylori, or decreased mucosal defence such as the host producing an abnormal weaker mucus layer or making insufficient amounts of growthregulatory peptides. It is more likely, however, that the reason why only subpopulations of individuals go on to get disease is that they have a combination of the two (Fig. 3).

\section{Dietary modifications and growth factors}

There is increasing evidence that dietary modification can result in modulation of growth factor concentrations. A good example of this is provided by the series of experiments showing that lumen EGF concentrations alter in response to diet. We showed that lumen EGF is rapidly digested by residual proteases in the fasting small intestines of human subjects. This effect was blocked, however, by the presence of food proteins which acted as competitive substrates for the enzymes (Playford et al. 1993). The concentration of lumen growth peptides, therefore, will alter markedly in response to

\section{Diseased GI tract}

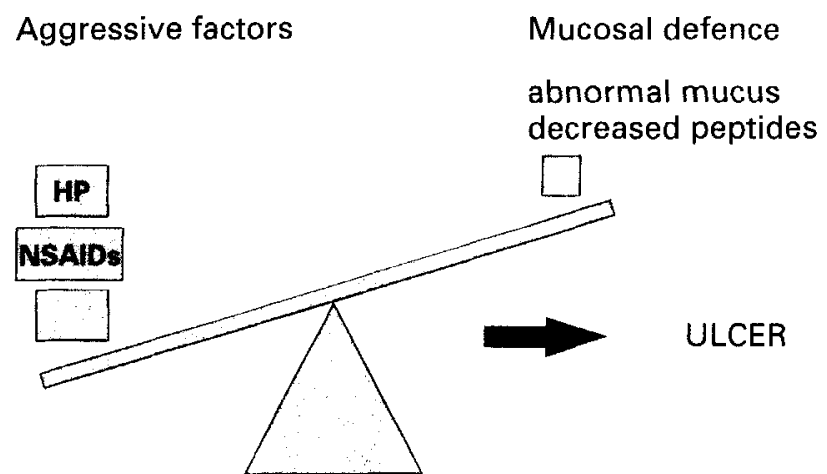

Fig. 3. Disease (ulceration) occurs when there is an inbalance, usually resulting from increased aggressive factors (such as taking nonsteroidal anti-inflammatory drugs (NSAID) or having the bacteria Helicobacter pylori (HP) present in the stomach) associated with reduced defence mechanisms (such as weakened mucus layer and reduced regulatory peptides). Gl, gastrointestinal.

Table 3. Reviews relating to cytokines and growth factors

\begin{tabular}{|c|c|c|}
\hline & Reference & No. of references cited \\
\hline \multicolumn{3}{|l|}{ General reviews } \\
\hline Peptides and gastrointestinal mucosal integrity & Playford (1995) & 24 \\
\hline Cytokines in intestinal inflammation & Sartor (1994) & 17 \\
\hline $\begin{array}{l}\text { Distribution of peptides associated with gastric mucosal } \\
\text { healing and neoplasia }\end{array}$ & Sarraf et al. (1995) & 86 \\
\hline \multicolumn{3}{|l|}{ Specific peptide reviews } \\
\hline Trefoil peptides & Plaut (1997) & 14 \\
\hline \multirow[b]{2}{*}{ Epidermal growth factor } & & \\
\hline & $\begin{array}{l}\text { Barnard et al. (1995) } \\
\text { Goodlad \& Wright (1996) }\end{array}$ & $\begin{array}{r}204 \\
92\end{array}$ \\
\hline \multirow[t]{3}{*}{ 'Epidermal growth factor' and transforming growth factor $\alpha$} & Goodlad \& Wright (1995) & 29 \\
\hline & Barnard et al. (1995) & 204 \\
\hline & Uribe \& Barret (1997) & 160 \\
\hline Insulin-like growth factor-1 & Benito et al. (1996) & 100 \\
\hline
\end{tabular}


(A)

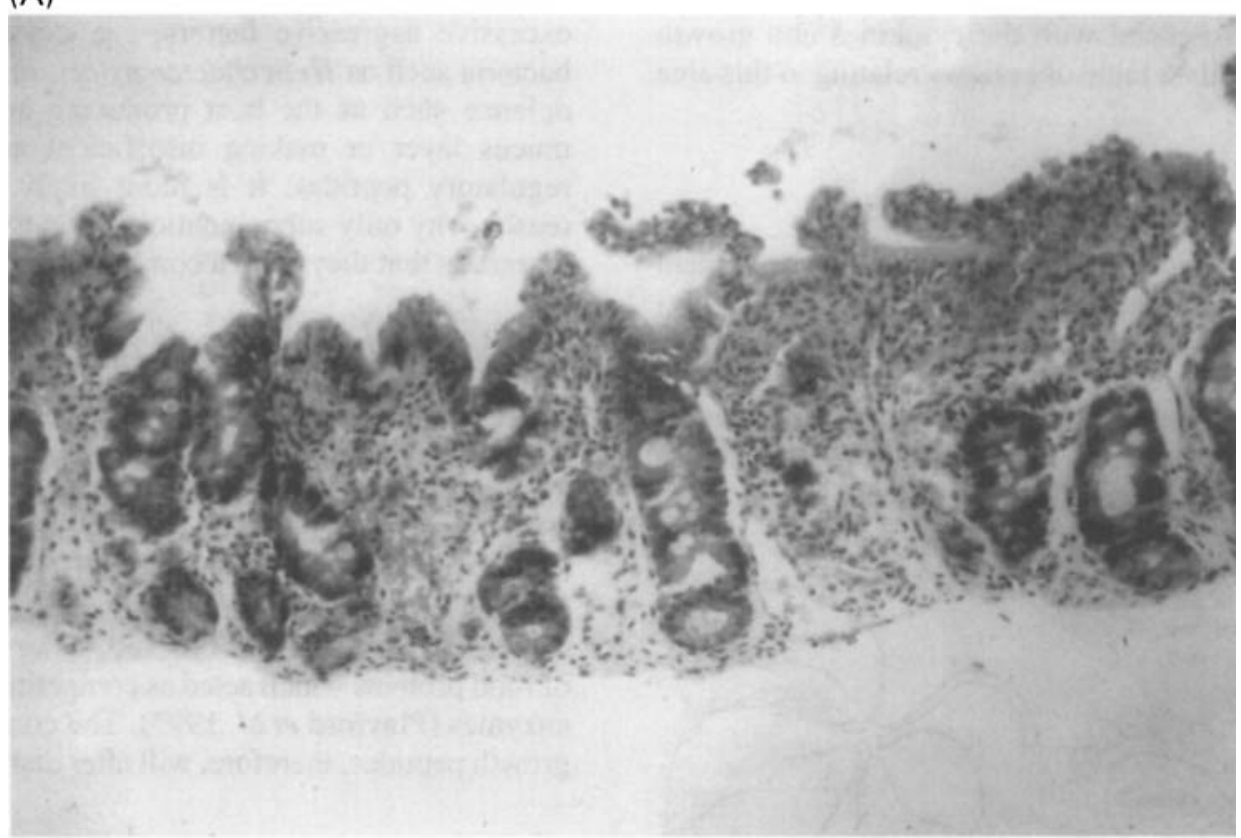

(B)

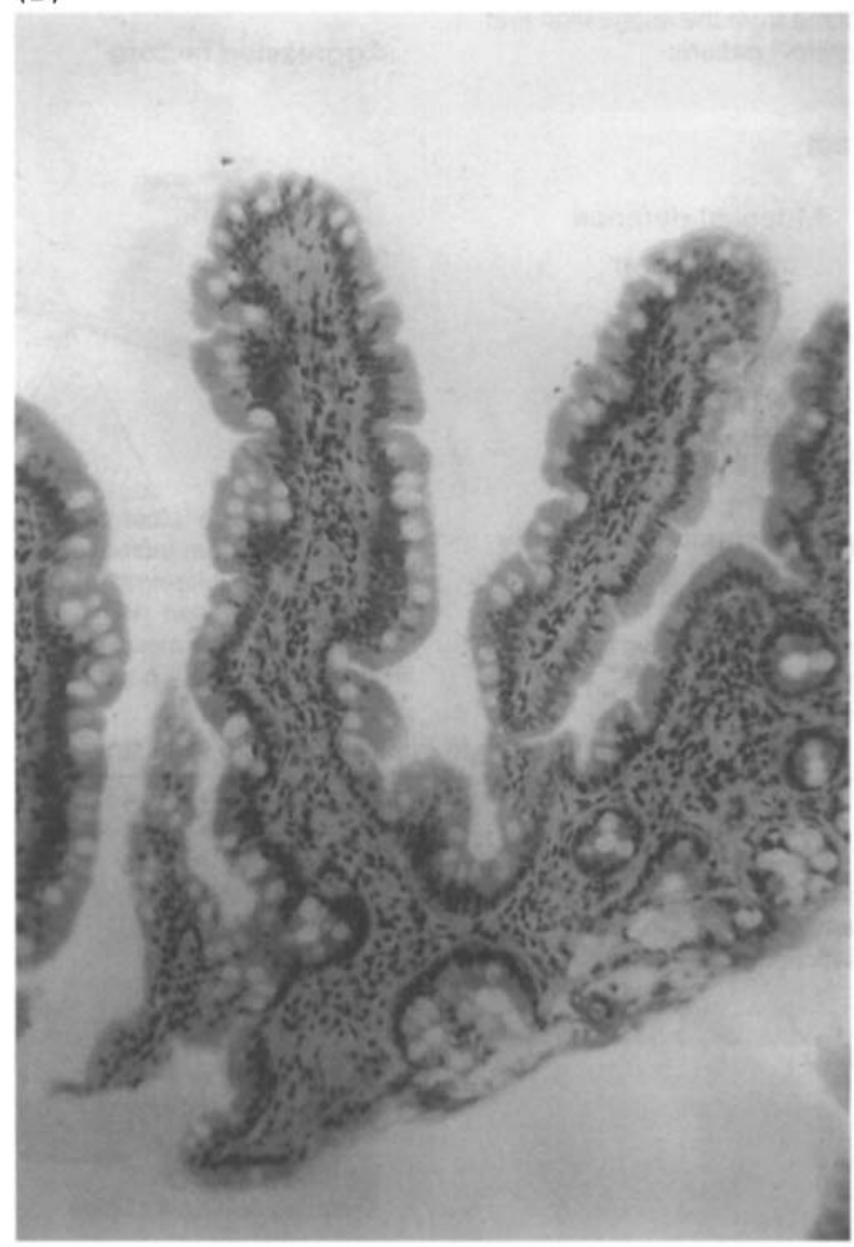

Fig. 4. Haematoxylin and eosin stain of small intestinal biopsies of a child with necrotizing enteritis. (A) Before therapy, the mucosa is virtually completely ulcerated; (B) $10 \mathrm{~d}$ after starting an infusion of epidermal growth factor, the mucosa is virtually regenerated. 
the form of diet being taken. This sort of phenomenon might contribute to the mechanism underlying the trophic effect of food.

\section{Growth factors and cancer}

Adenomas and carcinomas are known to produce increased amounts of growth-modulatory agents such as EGF receptor ligands (Steel, 1989; Hanby et al. 1993) and glycineextended gastrin (Ciccotosto et al. 1995) as well as increased amounts of their receptors. These growth factors may, therefore, act in an autocrine and paracrine fashion, stimulating growth of the tumour. Blockade of these growth factor receptors provides a novel potential approach for the treatment of such tumours.

\section{Clinical applications of growth factors}

Naturally-occurring sources of growth factors

Colostrum is the form of milk produced during the first few days after birth. It is rich in antibodies, anti-bacterial peptides and growth factors. Preliminary studies suggest that oral administration of bovine colostrum is able to reduce indomethacin-induced intestinal injury (Playford et al. 1997). Clinical trials are underway to investigate the potential role of bovine colostrum in reducing non-steroidal anti-inflammatory drug-induced intestinal injury and also for the treatment of chemotherapy-induced mucositis and inflammatory bowel disease.

\section{Recombinant peptides}

Artificially-produced peptides are now available at a (relatively) reasonable price for clinical use. There is much interest in their potential value for gastroenterological disease. One recombinant peptide that has already found a place in clinical gastroenterology is interferon- $\alpha$, used for the treatment of chronic viral hepatitis. Clinical data for the use of various other growth factors, cytokines and cytokine inhibitors in ulcerative conditions of the bowel, particularly inflammatory bowel disease, are now beginning to be published (Playford, 1997b).

A prime example of the exciting therapeutic potential of recombinant peptides is shown by the case of an 8-month-old female with severe life-threatening necrotizing enterocolitis (an extreme ulcerative condition of unknown origin affecting the small and large bowel of young children). Standard medical therapy had proved ineffective and, therefore, a continuous intravenous infusion of EGF was administered. Within $5 \mathrm{~d}$ the ulcerated bowel began to look normal and the patient made a miraculous recovery (Fig. 4 (A and B); Sullivan et al. 1991).

\section{Summary}

Growth factors play a key role in maintaining gut integrity and in stimulating repair. By understanding their physiological function we can use this information to apply to the treatment of conditions in which mucosal homeostasis has broken down.

\section{Acknowledgements}

The authors acknowledge funding from MRC and the Wellcome Trust.

\section{References}

Baldwin GS \& Whitehead RH (1994) Gut hormones, growth and malignancy. Bailliere's Clinical Endocrinology and Metabolism 8, 185-214

Barnard JA, Beauchamp RD, Russell WE, Dubois RN \& Coffey RJ (1995) Epidermal growth factor-related peptides and their relevance to gastrointestinal pathophysiology. Gastroenterology 108, 564-580.

Benito M, Valverde AM \& Lorenzo M (1996) IGF-1: a mitogen also involved in differentiation process in mammalian cells. International Journal of Biochemistry and Cell Biology $\mathbf{2 8}$, 499-510.

Ciccotosto GD, McLeish A, Hardy KJ \& Shulkes A (1995) Expression, processing, and secretion of gastrin in patients with colorectal-carcinoma. Gastroenterology 109, 1142-1153.

Dignass AU \& Podolsky DK (1993) Cytokine modulation of intestinal epithelial cell restitution: central role of transforming growth factor $\beta$. Gastroenterology $105,1323-1332$.

Dinarello CA (1994) The interleukin-1 family: 10 years of discovery. FASEB Journal 8, 1314-1325.

Egger B, Procacino F, Lakshmanan J, Reinshagen M, Hoffman P, Patel A, Reuben W, Gnakkan S, Liu L, Barajas L \& Eysselein VE (1997) Mice lacking transforming growth factor $\alpha$ have an increased susceptibility to dextran sulphate-induced colitis. Gastroenterology 113, 825-832.

Goodlad RA, Wilson TJD, Lenton W, Gregory H, McClagh KG \& Wright NA (1987) Intravenous but not intragastric urogastrone (EGF) is trophic to the intestine of parenterally fed rats. Gut $\mathbf{2 8}$, 573-582.

Goodlad RA \& Wright NA (1995) Epidermal growth factor and transforming growth factor-alpha actions on the gut. European Journal of Gastroenterology and Hepatology 7, 928-932.

Goodlad RA \& Wright NA (1996) Epidermal growth factor (EGF). Bailliere's Clinical Gastroenterology 10,33-47.

Hanby AM, Poulsom R, Singh S, Elia G, Jeffrey RE \& Wright NA (1993) Hyperplastic polyps: a cell lineage which both synthesizes and secretes trefoil-peptides and has phenotypic similarity with the ulcer-associated cell lineage. American Journal of Pathology 142, 663-668.

Hui WM, Chen BW \& Kung AW (1993) Effect of epidermal growth factor on gastric blood flow in rats; possible role in mucosal protection. Gastroenterology 104, 1605-1610.

Ishikawa S, Cepinskas G, Specian RD, Itoh M \& Kuietys PR (1994) Epidermal growth factor attenuates jejunal mucosal injuryinduced by oleic-acid: role of mucus. American Journal of Physiology 30, 1067-1077.

Lamprecht SA, Schwartz B \& Glicksman A (1989) Transforming growth factor $\beta$ in intestinal epithelial differentiation and neoplasia. Anticancer Research 9, 1877-1882.

Plaut AG (1997) Trefoil peptides in the defense of the gastrointestinal tract. New England Journal of Medicine 336, 506-507.

Playford RJ (1995) Leading article: Peptides and mucosal integrity. Gut 37, 595-597.

Playford RJ (1997a) Trefoil peptides: What are they and what do they do? Journal of the Royal College of Physicians 31, $37-41$.

Playford RJ (1997b) Leading article: Recombinant peptides for gastrointestinal ulceration: still early days. Gut 40, 286-287.

Playford RJ, Andenekan RO, Marchbank T, Boulton R, Johnson W \& Goodlad RA (1997) Bovine colostrum is prophylactic against 
indomethacin-induced intestinal injury. Gastroenterology 112, 394.

Playford RJ, Batten JJ, Freeman TC, Beardshall K, Vesey D, Fenn GC, Baron JH \& Calam J (1991) Gastric output of pancreatic secretory trypsin inhibitor is increased by misoprostol. Gut $\mathbf{3 2}$, 1396-1400.

Playford RJ, Hanby A, Gschmeissner S, Peiffer LP, McGarrity T \& Wright NA (1996) The epidermal growth factor receptor (EGF-R) is present on the basolateral, but not the apical, surface of enterocytes in the human gastrointestinal tract. Gut 39, 262-266.

Playford RJ, Marchbank T, Calam J \& Hansen FH (1995a) EGF is digested to smaller, less active, forms in acidic gastric juice. Gastroenterology 108, 92-101.

Playford RJ, Marchbank T, Chinnery R, Thim L \& Hanby AH (1995b) Human spasmolytic polypeptide is a cytoprotective agent which stimulates cell migration. Gastroenterology 108 , 108-116.

Playford RJ, Watanaba P, Woodman AC, Deprez PH \& Calam J (1993) Effect of luminal growth factor preservation on intestinal growth. Lancet 341, 843-848.

Playford RJ \& Wright NA (1996) Leading article: Why is EGF present in the gut lumen? Gut 38, 303-305.
Sarraf CE, Alison MR, Ansari TW \& Wright NA (1995) Subcellular distribution of peptides associated with gastric mucosal healing and neoplasia. Microscopy Research and Technique 31, 234-237.

Sartor RB (1994) Cytokines in intestinal inflammation; pathophysiological and clinical considerations. Gastroenterology 106, 533-539.

Steel CM (1989) Peptide regulatory factors and malignancy. Lancet ii, $30-34$.

Sullivan PB, Brueton MJ, Tabara Z, Goodlad RA, Lee CY \& Wright NA (1991) Epidermal growth factor in necrotising enteritis. Lancet 338, 53-54.

Svanes K, Itoh S, Takeuchi K \& Silen W (1982) Restitution of the surface epithelium of the in vitro gastric mucosa after damage with hypermolar sodium chloride. Gastroenterology $\mathbf{8 2}$, 1409-1426.

Uribe JM \& Barret KE (1997) Non-mitogenic actions of growth factors: an integrated view of their role in intestinal physiology and pathophysiology. Gastroenterology 112, 255-268.

Wright NA, Hoffmann W, Otto WR, Rio MC \& Thim L (1997) Rolling in the clover:trefoil factor family (TFF)domain peptides, cell migration and cancer. FEBS Letters 408 , $121-123$. 